\title{
Near-Surface Studies of the Changes to the Structure and Mechanical Properties of Human Enamel under the Action of Fluoride Varnish Containing CPP-ACP Compound
}

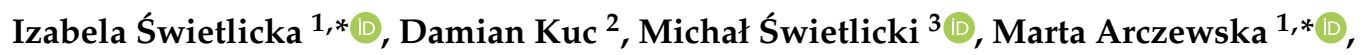

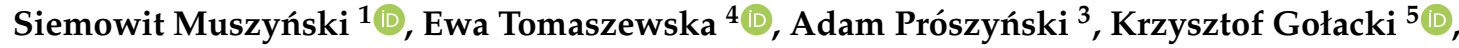 \\ Jerzy Błaszczak ${ }^{6}$, Krystian Cieślak ${ }^{7}$, Daniel Kamiński ${ }^{8}$ (D) and Maria Mielnik-Błaszczak ${ }^{2}$ \\ 1 Department of Biophysics, Faculty of Environmental Biology, University of Life Sciences in Lublin, \\ 20-950 Lublin, Poland; siemowit.muszynski@up.lublin.pl \\ 2 Chair and Department of Paediatric Dentistry, Medical University of Lublin, 20-059 Lublin, Poland; \\ damian.kuc@umlub.pl (D.K.); maria.mielnik-blaszczak@umlub.pl (M.M.-B.) \\ 3 Department of Applied Physics, Faculty of Mechanical Engineering, Lublin University of Technology, \\ 20-618 Lublin, Poland; m.swietlicki@pollub.pl (M.Ś.); a.proszynski@pollub.pl (A.P.) \\ 4 Department of Animal Physiology, Faculty of Veterinary Medicine, University of Life Sciences in Lublin, \\ 20-950 Lublin, Poland; ewarst@interia.pl \\ 5 Department of Mechanical Engineering and Automatics, Faculty of Production Engineering, University of \\ Life Sciences in Lublin, 20-612 Lublin, Poland; krzysztof.golacki@up.lublin.pl \\ 6 Weglin-Medical, 20-716 Lublin, Poland; blaszczakjerzy@gmail.com \\ 7 Institute of Renewable Energy Engineering, Faculty of Environmental Engineering, Lublin University \\ of Technology, 20-618 Lublin, Poland; k.cieslak@pollub.pl \\ 8 Department of Crystallography, Faculty of Chemistry, Maria Curie-Sklodowska University, \\ 20-031 Lublin, Poland; daniel.kaminski@umcs.pl \\ * Correspondence: izabela.swietlicka@up.lublin.pl (I.Ś.); marta.arczewska@up.lublin.pl (M.A.)
}

Received: 10 March 2020; Accepted: 11 May 2020; Published: 14 May 2020

\begin{abstract}
Changes to the features of the enamel surface submitted to induced demineralisation and subsequent remineralisation were studied. The in vitro examination was conducted on polished slices of human molar teeth, divided in four groups: the untreated control $(n=20)$, challenged by a demineralisation with orthophosphoric acid $\left(\mathrm{H}_{3} \mathrm{PO}_{4}\right)(n=20)$, and challenged by a demineralisation following remineralisation with fluoride $(\mathrm{F})$ varnish containing casein phosphopeptides $(\mathrm{CPP})$ and amorphous calcium phosphate (ACP) compounds $(n=20)$. The specimens' enamel surfaces were subjected to analysis of structure, molecular arrangement, mechanical features, chemical composition, and crystalline organization of apatite crystals. Specimens treated with acid showed a significant decrease in crystallinity, calcium, and phosphorus levels as well as mechanical parameters, with an increase in enamel surface roughness and degree of carbonates when compared to the control group. Treatment with fluoride CPP-ACP varnish provided great improvements in enamel arrangement, as the destroyed hydroxyapatite structure was largely rebuilt and the resulting enamel surface was characterised by greater regularity, higher molecular and structural organisation, and a smoother surface compared to the demineralised one. In conclusion, this in vitro study showed that fluoride CPP-ACP varnish, by improving enamel hardness and initiating the deposition of a new crystal layer, can be an effective remineralising agent for the treatment of damaged enamel.
\end{abstract}

Keywords: enamel surface; fluoride varnish; CPP-ACP; AFM; Raman microspectroscopy; XRD; EDS; nanoindentation 


\section{Introduction}

Enamel consists on average of $95 \%$ hydroxyapatite (HA) crystals $\left(\mathrm{Ca}_{10}\left(\mathrm{PO}_{4}\right)_{6}(\mathrm{OH})_{2}\right), 4 \%$ water, and $1 \%$ organic material and is characterised by the strict organic-inorganic hybrid organization. HA crystallites, along with the remaining organic material and water, are arranged into bundles. These bundles establish greater, species-dependent structures known as rods or prisms with interprism regions between them [1]. Natural HA observed in teeth can have different substitutes for $\mathrm{Ca}^{2+}\left(\mathrm{Na}^{+}\right.$, $\mathrm{K}^{+}$, and $\left.\mathrm{Mg}^{2+}\right)$ and for phosphate and hydroxyl $\left(\mathrm{CO}_{3}{ }^{2-}, \mathrm{F}^{-}, \mathrm{HPO}_{4}{ }^{2-}, \mathrm{Cl}^{-}\right.$, and $\left.\mathrm{H}_{2} \mathrm{O}\right)$ in comparison to those observed in the HA stoichiometric form [2,3]. The main difference between the HA model and biological apatites is the presence of significant amounts of carbonate ions in all the mineralized biological tissues [1].

In the oral environment, tooth structure undergoes alternate demineralisation and remineralisation processes, which influence structural and morphological parameters of enamel. Demineralisation is mainly caused by acids present in food, juices, or other beverages or may be a result of decreased salivary flow, gastroesophageal reflux, or eating disorders [4,5]. Remineralisation, in turn, develops as restoration of partially dissolved crystals, new crystal formation, or growth of surviving crystals [6]. Demineralization and remineralization can be considered as a dynamic processes, characterized by the flow of calcium and phosphate out of and back into tooth enamel [7]. Both remineralisation and demineralisation influence structural and morphological parameters of enamel, altering its features and changing its arrangement. Enamel is unable to regenerate, self-repair, or remodel itself as it contains no cells [8]. The natural protective mechanisms neutralizing and clearing the acids or enhancing remineralisation of enamel by providing inorganic ions $[9,10]$ is frequently inadequate to maintain strong tissue. Then, the remineralisation process might be supported by a range of physical or chemical factors, for example, lasers [11,12], fluoride-containing treatments, substances involving casein phosphopeptides (CPP) and amorphous calcium phosphate (ACP) or a combination of them [13-16].

$\mathrm{CPP}-\mathrm{ACP}$ is a bioactive milk product that has been found to enhance remineralization and prevents dental caries. As CPP have the ability to stabilize ACP in the metastable solution, $\mathrm{CPP}-\mathrm{ACP}$ provides a pool of bio-available calcium and phosphate that can maintain the supersaturation of saliva [17]. Calcium and phosphate concentration within the subsurface lesions is kept high, which results in remineralization [18]. Fluoride ions, in turn, substitute for a hydroxyl column in the apatite structure [19]. When a tooth surface is equilibrated with oral fluids containing fluoride, the most stable phase of fluorapatite (FA) is produced, which effectively maximizes the stability of the tooth mineral in the oral environment [19]. In supersaturated solutions, where the fluoride is available together with calcium and phosphate, fluoride ions are incorporated into the apatite crystal lattice through precipitation and growth reactions. Therefore, a combination of fluoride and CPP-ACP is regarded as an optimally efficient remineralisation agent on enamel lesions when compared with a fluoride treatment alone [20]. New, rebuilt crystalline structures, composed of fluoridated hydroxyapatite and fluorapatite, are characterised by a higher resistance to acid attack than the original ones [20].

The aim of this study was to examine in vitro the effect of a fluoride varnish containing CPP-ACP on the remineralization of artificially demineralized human enamel. As the action of chemical substances supporting the remineralisation process is mainly visible on the tooth surface, therefore, in the presented work, we wanted to concentrate particularly on the enamel surface. To recognise the enamel's surface features in a maximally wide range, we tested its morphology, chemical composition, mechanical properties, crystal and molecular arrangement after demineralisation, and subsequent remineralisation with CPP-ACP fluoride varnish measurements involving atomic force microscopy (AFM), scanning electron microscopy (SEM), energy-dispersive X-ray spectroscopy (EDS), Raman microspectroscopy, $\mathrm{X}$-ray diffraction (XRD) technique, and nanoindentation. 


\section{Materials and Methods}

Examinations were conducted on slices of human third molar teeth that belonged to the control group, were demineralised with an orthophosphoric acid $\left(\mathrm{H}_{3} \mathrm{PO}_{4}\right)$, or were demineralized and then underwent remineralisation under the action of fluoride varnish (MI Varnish, Tokyo, Japan) containing casein phosphopeptides and amorphous calcium phosphate.

Teeth were extracted for orthodontic reasons and were caries-free. All subjects gave their informed consent for inclusion before they participated in the study. The study was conducted in accordance with the Declaration of Helsinki, and the experiment was approved by The Local Ethics Committee at the Medical University of Lublin (reference number KE-0254/257/2017) on 26 October 2017. After preparation, the enamel surfaces were subjected to multidimensional analysis. The detailed description of the experimental procedures is provided below and can be tracked in the scheme (Figure 1).

\section{Timeline}

\section{Extraction}

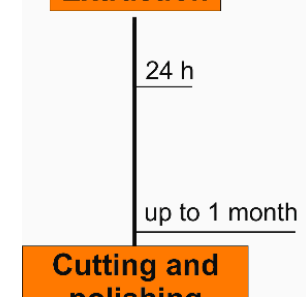

\section{Third molars $(n=30)$}

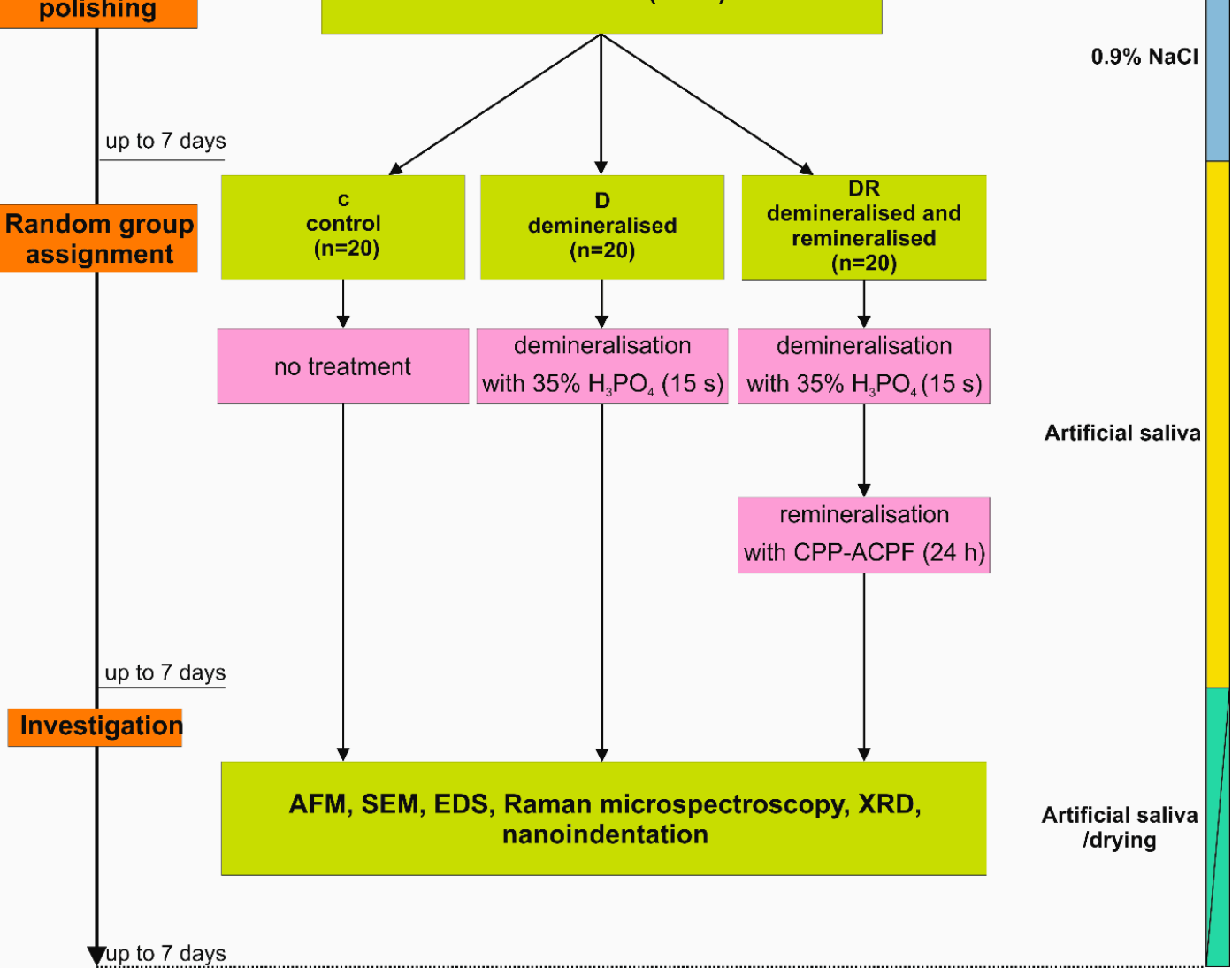

Figure 1. Experimental design. c-control, D—demineralised group, DR-demineralised and then remineralised group. 


\subsection{Sample Preparation}

Extracted teeth were disinfected in aqueous $0.5 \%$ Chloramine-T solution (Poch S.A., Gliwice, Poland) dissolved in deionized water at $4{ }^{\circ} \mathrm{C}$ for $24 \mathrm{~h}$, washed with deionized water, dried in a desiccator [21], and placed in a $0.9 \mathrm{NaCl}$ solution at $4{ }^{\circ} \mathrm{C}$ for no longer than a month. Prepared molars ( $n=30)$ were cut longitudinally into slices (2-4 from each molar) with an average thickness of $1.5( \pm 0.025) \mathrm{mm}$ using a low-speed diamond saw (Figure 2). To obtain a flat, scratch-free surface, teeth slices were polished with 1500, 2000, 2500, 3000, and 6000 grit waterproof silicon carbide paper, followed by 3,2 , and $1 \mathrm{~mm}$ aluminium oxide, and then cleaned and washed for $20 \mathrm{~s}$ in distilled water. Samples with cracks or other defects were removed from the experiment. The cut fragments were stored in a $0.9 \% \mathrm{NaCl}$ solution at $4{ }^{\circ} \mathrm{C}$ until treatment (demineralisation and remineralisation), for no longer than 7 days. Teeth slices were divided into three sets ( $n=20$ for each group) according to their pre-treatments before testing: the first group of slices belonged to the control (c) and for that group no treatment was applied, those in the second group were demineralised (D), while those in the third were demineralised and next remineralised (DR). Demineralisation was done by the immersion of the molar slices for $15 \mathrm{~s}$ in $35 \%$ orthophosphoric acid $\left(\mathrm{H}_{3} \mathrm{PO}_{4}\right)$, which is known to cause dissolution of enamel minerals and is widely applied in studies concerning carries simulation $[15,22]$. Next, slices were rinsed by deionized water (Millipore, Bedford, MA, USA) for $20 \mathrm{~s} \mathrm{[23].} \mathrm{Teeth} \mathrm{from} \mathrm{the} \mathrm{other} \mathrm{group,}$ after demineralisation, were covered with varnish according to the manufacturers' instructions and left for $24 \mathrm{~h}$ in a moist environment (artificial saliva, $\mathrm{pH} 7.0$ [24]). After this time, the varnish was removed from the surface and the samples were cleaned with cotton swabs soaked in acetone and rinsed with deionised water [13,25].

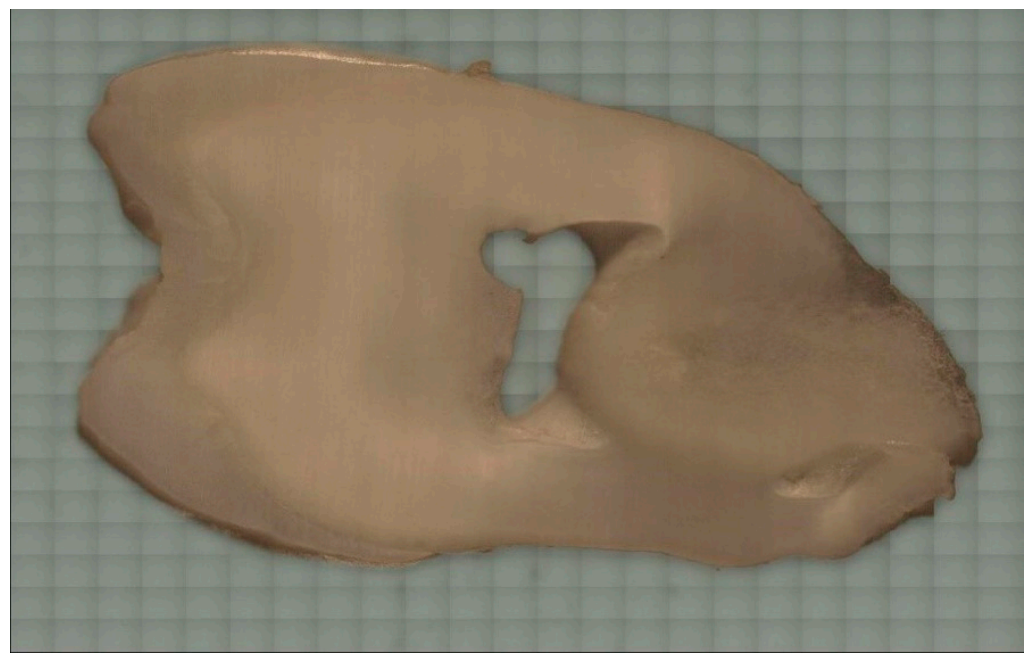

Figure 2. Example slice of human molar.

Obtained teeth slices from the experimental groups were stored at $4{ }^{\circ} \mathrm{C}$ in artificial saliva (changed daily) and were subjected to analysis within no longer than 7 days.

\subsection{AFM Measurements and Roughness Calculation}

Examination was undertaken on $n=30$ teeth slices ( $n=10$ for each group). Tooth fragments, previously dried in a desiccator under vacuum conditions for $24 \mathrm{~h}$, were mounted on the sapphire plates by an adhesive tape. Enamel surfaces were initially examined under an optical microscope to determine three regions intended for AFM measurements. The measurements were carried out under atmospheric conditions in a semi-contact mode, at room temperature, and with relative humidity of 25\% by NTEGRA Prima (NT-MDT, Moscow, Russia). Silicon cantilevers $125 \mu \mathrm{m}$ long, $4.0 \mu \mathrm{m}$ thick, with a tip radius of $10 \mathrm{~nm}$, and the average resonant frequency of $310 \mathrm{kHz}$ were used. For each slice, three areas in size $30 \mu \mathrm{m} \times 30 \mu \mathrm{m}$ were investigated with a slow scan rate of $1 \mathrm{~Hz}$ and with a resolution 
of $512 \times 512$ pixels per image. The enamel surface was pictured in the height, magnitude, and phase domains. The parameters describing surface roughness (average roughness $S_{a}$, root mean square roughness $S_{q}$, the vertical distance between the maximum height and the maximum depth $S_{z}$, and the average height calculated over the five highest peaks $p$ and five deepest valleys $v S_{10}$ ) were determined for a height function $Z_{\mathrm{ij}}(x, y)$ defined over a certain $X Y$ plane, according to Equations (1) to (4):

$$
\begin{gathered}
S_{a}=\frac{1}{N_{x} N_{y}} \sum_{j=1}^{N_{y}} \sum_{i=1}^{N_{x}}\left|Z_{i j}\right|, \\
S_{q}=\sqrt{\frac{1}{N_{x} N_{y}} \sum_{j=1}^{N_{y}} \sum_{i=1}^{N_{x}} Z_{i j}^{2},} \\
S_{z}=S_{p}+S_{v}, \\
S_{10}=\frac{\sum_{i=1}^{5}\left|Z_{p i}\right|+\sum_{i=1}^{5}\left|Z_{v i}\right|}{5},
\end{gathered}
$$

where $N_{x}$ and $N_{y}$ are the sampling rates along the $X$ and $Y$ axes, respectively, $S_{p}$ is the maximum height of the surface defined with respect to the mean surface, and $S_{v}$ is defined as the maximum depth of the surface defined with respect to the mean surface [26,27].

\subsection{SEM Imaging and EDS Measurements}

To perform the morphological analysis of enamel, a scanning electron microscope (SU3500, Hitachi Ltd., Tokyo, Japan) working at $20 \mathrm{kV}$ in high vacuum conditions was used. Prior to introducing the samples to the SEM chamber ( $n=3$ from the control, $n=3$ demineralised, and $n=3$ demineralised then remineralised), slices were dried in a desiccator for $24 \mathrm{~h}$, and then coated with an ultrathin gold (Au) film with ion sputtering equipment (Sputter Coater 108auto, Cressington Sci. Instr., Watford, UK). The enamel surface was imaged with $3000 \times$ and $8000 \times$ magnification.

In order to establish the element composition of the teeth slices, during SEM, imaging energy-dispersive spectrometry (EDS) was performed. An UltraDry high-performance X-ray energy dispersive Silicon Drift detector (Thermo Scientific Noran System 7, Thermo Electron Scientific Instruments LLC, Madison, WI, USA) was used. The detector was operated in a high vacuum at $20 \mathrm{kV}$ with a working distance $10 \mathrm{~mm}$. X-ray spectra were acquired and analysed in terms of percentage composition of elements included in the teeth, especially $\mathrm{Ca}, \mathrm{P}$, and $\mathrm{F}$.

\subsection{Raman Spectra Collection and Data Analysis}

The Raman spectra were collected on a NTEGRA Spectra confocal spectrometer (NT-MDT, Moscow, Russia) under excitation with a diode laser operating at a wavelength of $532 \mathrm{~nm}$. The incident laser power applied to the sample was $16 \mathrm{~mW}$ and a 600 lines/mm grating with a blaze wavelength of $600 \mathrm{~nm}$ was applied. A $\times 100 / 0.7$ objective was used to focus the laser light on the sample while a charge-coupled device $(C C D)$ camera $(1650 \times 200$ pixel matrix), operating at $230 \mathrm{~K}$, was applied to detect the scattered light. Raman maps were recorded with a sampling frequency of $0.25 \mu \mathrm{m}$ in both $x$ and $y$ directions. For each tooth ( $n=3$ for each group), two maps of size $5 \mu \mathrm{m} \times 5 \mu \mathrm{m}$ each were acquired. All the Raman spectra were collected within a spectral range of $100-2000 \mathrm{~cm}^{-1}$. The spectral resolution amounted to the average of $2.44 \mathrm{~cm}^{-1}$. Individual Raman spectra were analysed using the Grams/AI 8.0 (Thermo Scientific, Waltham, MA, USA). Due to the high dependence of Raman spectra from the HA crystallites orientation in the c-axis [28-31], further analysis spectra from the rod regions only were selected [32]. All Raman spectra were corrected from the fluorescence input using a polynomial baseline function, smoothed by a 5-point Savitzky-Golay filter, and normalized using the $960 \mathrm{~cm}^{-1}$ (the $v_{1}$ mode) band characterized by its relative intensity. The band positions were performed according to Gaussian fitting functions after subtracting a polynomial baseline. 


\subsection{Single Crystal X-Ray Diffraction}

The samples ( $n=9,3$ for each group), were dried for $24 \mathrm{~h}$ before testing in vacuum conditions. Enamel surfaces were measured in a $\theta-2 \theta$ geometry (Rigaku XtaLAB, Tokyo, Japan). The diffractometer was equipped with a MicroMax-007 HF rotated anode X-ray source and a Pilatus $300 \mathrm{~K}$ area detector, working over a range of 6-110 deg with a resolution of $0.078 \mathrm{deg}$ and $10 \mathrm{~min}$ counting time per frame. The diameter of the X-ray beam was $0.1 \mathrm{~mm}$. The sample was rotated around the direction perpendicular to the $\theta-2 \theta$ plane (around the $z$ direction) for signal averaging from $0.1 \mathrm{~mm}$ sample slices. The measured frames were processed in CrysAlisPRO software (Rigaku, Tokyo, Japan). The Scherrer equation (Equation (5)) [33] was used to calculate the mean size of the nanocrystallites:

$$
D=\frac{K \lambda}{\beta \cos \theta}
$$

where $\mathrm{D}$ is the mean size of the ordered crystalline domains, $\mathrm{K}$ is a constant related to the crystallite shape (0.9), $\beta$ is the full width of the peak at half of the maximum intensity (FWHM), counting the apparatus broadening of $0.08 \mathrm{deg}$ (limited by the detector resolution at $40 \mathrm{~mm}$ from the sample), $\lambda$ is the wavelength of $X$-ray radiation $(1.5407 \AA)$, and $\theta$ is the peak position. The sizes of the crystallites in the c crystallographic direction (z-axis) were calculated from the Miller index (002) [2,34]. Lattice spacing (interplanar spacing) $d_{h k l}$ was determined from the Bragg's law for the Miller indices (300) and (002) according to Equations (6) and (7):

$$
\begin{gathered}
\lambda=2 d_{h k l} \sin \theta_{h k l} \\
\frac{1}{d_{h k l}^{2}}=\frac{4}{3}\left(\frac{h^{2}+h k+k^{2}}{a^{2}}\right)+\frac{l^{2}}{c^{2}}
\end{gathered}
$$

where $h, k$, and $l$ are the Miller indices that are the reciprocal intercepts of the plane on the unit cell axes [2]. Lattice parameters a and $\mathrm{c}$ for the hexagonal unit cell were calculated to assess the type of the apatite (HA or FA) present in the enamel structure after remineralization. Furthermore, the crystallinity index (CI), which measures the percentage of crystalline material and is correlated to the degree of order within the crystals [35], was determined using Equation. (8):

$$
C I=\left(\frac{K_{A}}{F W H M_{002}}\right)^{3}
$$

where $\mathrm{K}_{\mathrm{A}}$ is a constant set to 0.24 and $\mathrm{FWHM}_{002}$ is the full width of the peak at half intensity of the (002) reflection peak [35]. Crystallographic planes and Bragg peaks were calculated using Mercury CSD 3.10.1 software (CCDC, Cambridge, UK) from the hydroxyapatite references (No. 2300273, Crystallography Open Database, and No. 96-901-0053, High Score Plus package software). The peak position and FWHM were determined from the Gaussian function fits to every peak with OriginPro 2016 software (OriginLab Co., Northampton, MA, USA) application.

\subsection{Nanoindentation Measurements}

Slices of molar teeth were dried in vacuum conditions prior to examination in order to avoid the adhesion effect [36]. The nanoindentation tests were carried out using the Ultra Nano Hardness Tester (UNHT CSM Instruments, Needham, MA, USA) with a diamond Berkovich indenter with a face angle of $65.3 \mathrm{deg}( \pm 0.3)$. The indentations were taken at room temperature using the linear loading mode with a max depth of $400 \mathrm{~nm}, 30 \mathrm{mN} / \mathrm{min}$ loading rate, and pauses of $10 \mathrm{~s}$. For a given penetration depth value, ten indentations were made for each sample ( $n=15,5$ for each group), and the average values of indentation hardness (HIT) and indentation elasticity (EIT) were calculated. 


\subsection{Data Analysis}

Statistical analysis was performed using Statistica13.1 (TIBCO Software Inc. Palo Alto, CA, USA) and OriginPro 2016 (OriginLab Co., Northampton, MA, USA) applications. After removal of outliers, the resulting dataset was checked for normality distribution by the Shapiro-Wilk test, while the homogeneity of the variance was checked using the Levene test. One-way ANOVA was applied to assess the differences among the examined groups (control (c), demineralised (D), and demineralised then remineralised (DR)) in terms of the parameters characterising the structure and organisation of the enamel surface. The significance level $p$ was set on 0.05 . After analysis, further post-hoc tests (Tukey) were carried out to ascertain the nature of the differences among groups.

\section{Results}

\subsection{Morphology and Chemical Composition}

The process of enamel surface treatment with an orthophosphoric acid caused a significant increase in surface roughness (Figure 3), indicating that the enamel's surface morphology underwent considerable changes. The average values of the roughness parameters in the demineralised group were about 6.5 times higher those of the control.
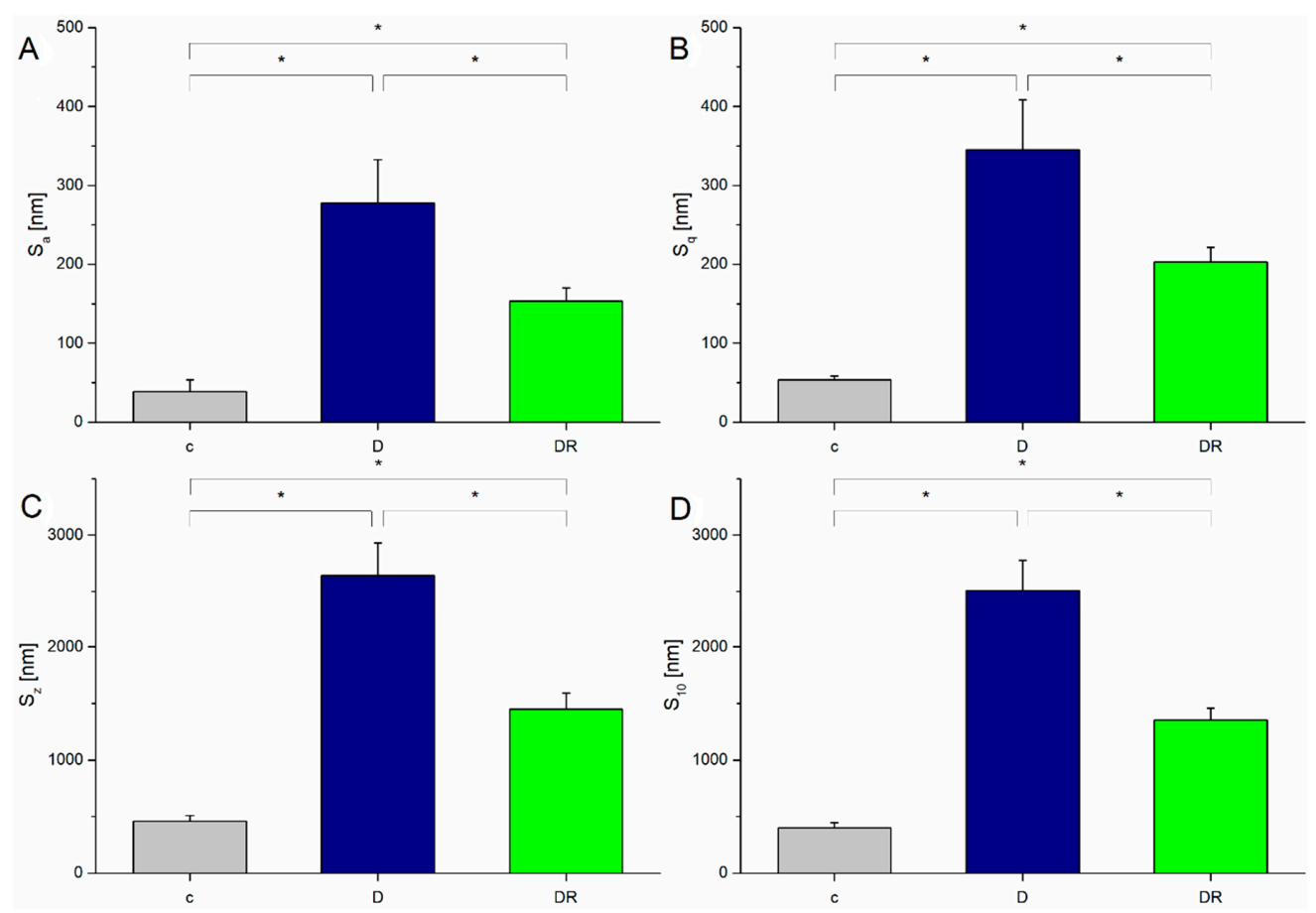

Figure 3. Roughness parameters of the enamel surface for the control (c), demineralised (D), and demineralised then remineralised (DR) enamel: (A) the average roughness $S_{a}$, (B) the root mean square roughness $S_{\mathrm{q}},(C)$ the vertical distance between the maximum height and the maximum depth $S_{z}$, (D) the average height calculated over the five highest peaks and five deepest valleys $S_{10}$. Roughness parameters were determined over a surface of $30 \mu \mathrm{m} \times 30 \mu \mathrm{m}$. Statistically significant (at $p<0.05$ ) differences between groups are marked with *.

The averaged values of the roughness measurements for each examined tooth slice are in Figures S1-S4.

When the height profile over the scanning distance $(30 \mu \mathrm{m})$ was considered (Figure 4$)$, it was clear that the acid-treated enamel surface became more irregular and asymmetrical. The maximum difference in the height for the control group was equal to $0.13 \mu \mathrm{m}$, while for the demineralised group it was $1.24 \mu \mathrm{m}$. Additionally, a registered demineralisation pattern (Figure 5, IB and IIB) revealed that 
the interprism regions and partially prism cores were damaged, which led to the occurrence of gaps and cracks on the enamel surface.

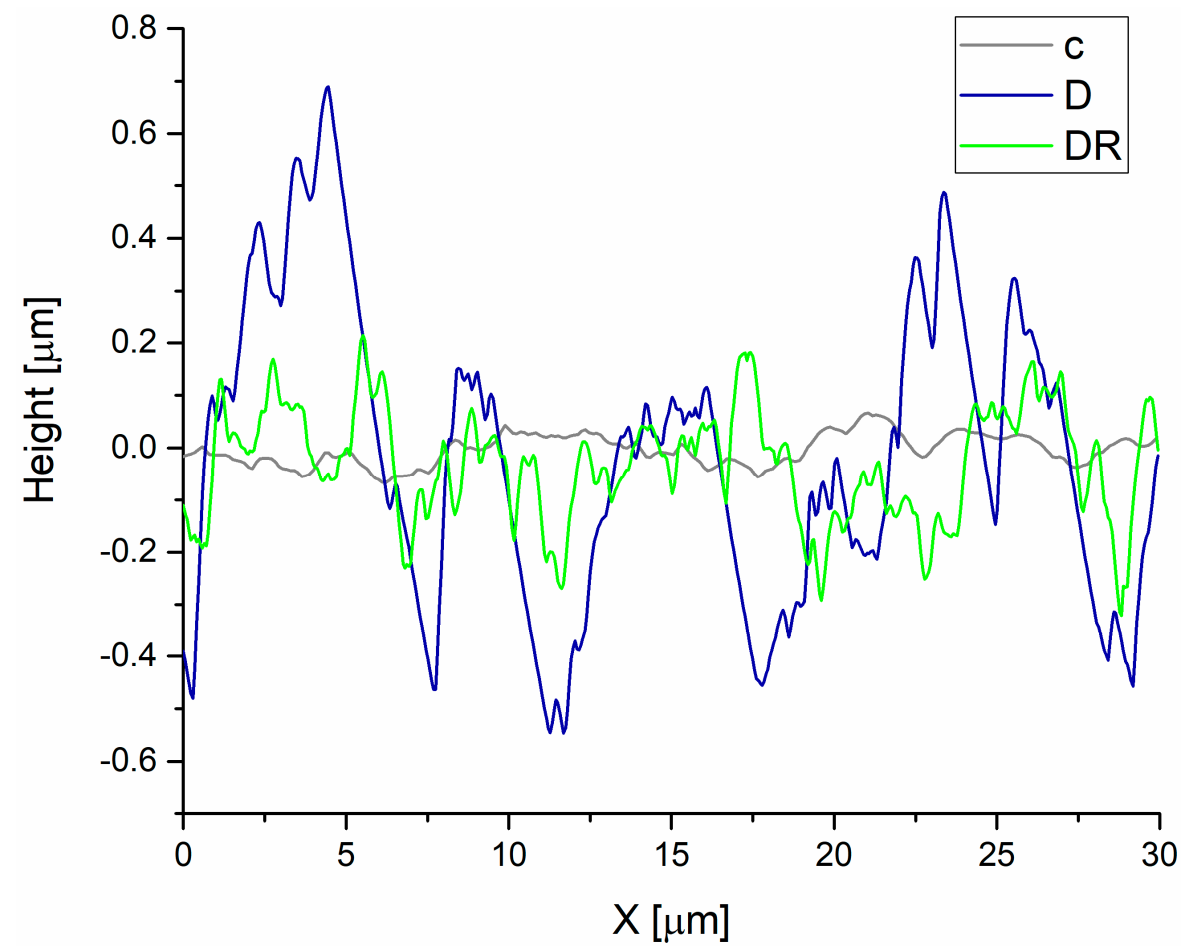

Figure 4. The average height profile for the control (c), demineralised (D), and remineralised then demineralised (DR) enamel over the scanning distance of $30 \mu \mathrm{m}$.
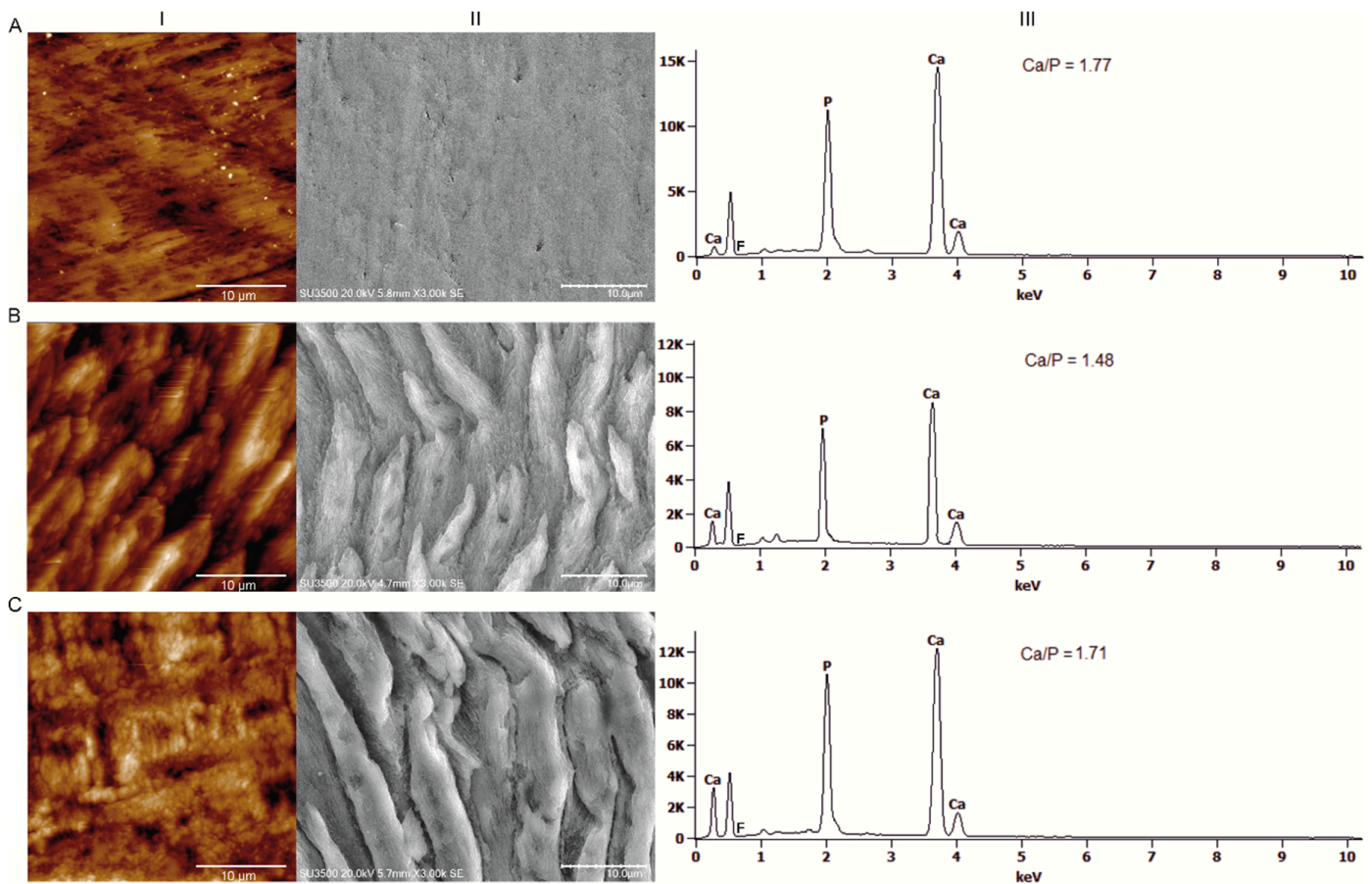

Figure 5. AFM (I) and SEM (II) scans of the enamel surface from the control (A), demineralised (B), and demineralised then remineralised (C) groups with corresponding EDS spectra (III) acquired from the enamel surfaces showing differences in the $\mathrm{Ca} / \mathrm{P}$ ratio for the examined groups. $\mathrm{The} \mathrm{Ca} / \mathrm{P}$ ratios are in Figure S5. a, b-groups that do not differ at $p<0.05$. 
Corresponding EDS spectra acquired from the enamel surfaces registered a significantly lower $\mathrm{Ca} / \mathrm{P}$ ratio in the D group compared to the control (Figure 5, IIIA, and IIIB). Varnish application resulted in a significant resmoothing of the enamel surface. The values of the roughness parameters for the DR group were about 1.8 times lower compared to those of the demineralised one (Figure 3). The enamel surface became more regular and organised, which can be observed on the height profiles (Figure 4) and both the AFM and SEM scans (Figure 5, IC and IIC). However, the roughness was still notably higher compared to the control. A significant difference in the roughness parameters was caused by an appearance of amorphous material deposits on the enamel surface, which are clearly visible in Figure 5, IIC. The maximum difference in the height over the scanning distance for the DR group was reduced to $0.54 \mu \mathrm{m}$. Additionally, EDS spectra showed an increase in the $\mathrm{Ca} / \mathrm{P}$ ratio compared to the demineralised group (Figure 5, IIIC).

\subsection{Structural Characterisation}

\subsubsection{Raman Spectroscopy Results}

In all groups, the Raman spectra of tooth enamel were dominated by phosphate bands of which there are four principal $\mathrm{PO}_{4}{ }^{3-}$ internal vibrational modes for apatite labelled $v_{1}$ to $v_{4}$ (Figure 6A). The most intensive $v_{1} \mathrm{PO}_{4}{ }^{3-}$ transition $\left(\sim 960 \mathrm{~cm}^{-1}\right)$ arises from the symmetric $\mathrm{P}-\mathrm{O}$ bond stretches in the mineral apatite component of enamel. The $v_{2}$ region of the spectrum, mainly a band located at $\sim 430 \mathrm{~cm}^{-1}$ is assigned to the symmetric bending mode of $\mathrm{PO}_{4}{ }^{3-}$. The other very weak bands in the spectrum are the $v_{3}$ of phosphate $\left(\sim 1040 \mathrm{~cm}^{-1}\right)$ and the $v_{1}$ of B-type carbonate $\left(\sim 1070 \mathrm{~cm}^{-1}\right)$, where $\mathrm{PO}_{4}{ }^{3-}$ is substituted by $\mathrm{CO}_{3}{ }^{2-}$. Finally, the bands located at $\sim 580$ and $608 \mathrm{~cm}^{-1}$, which belong to the $v_{4}$ vibrational modes, arise from the triply degenerated asymmetric bending vibrations [37].

A

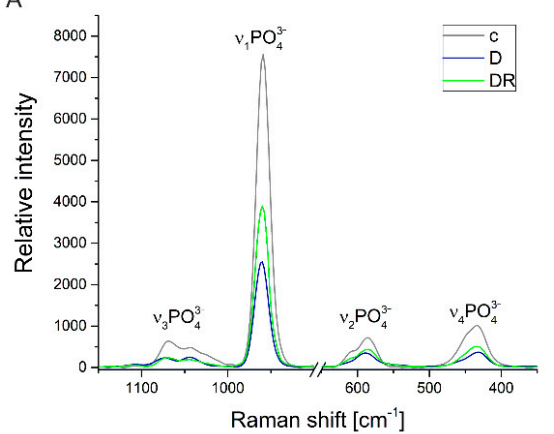

C

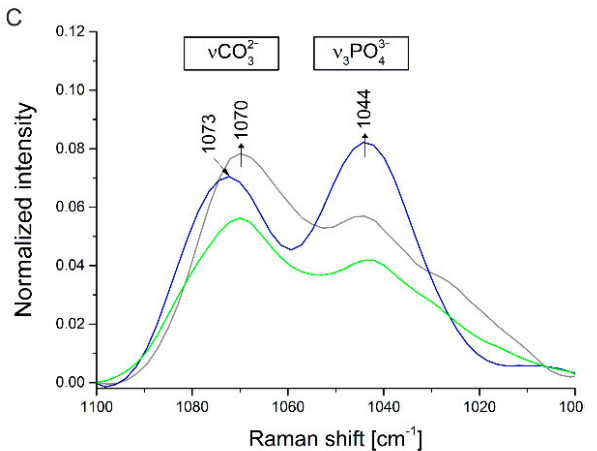

B

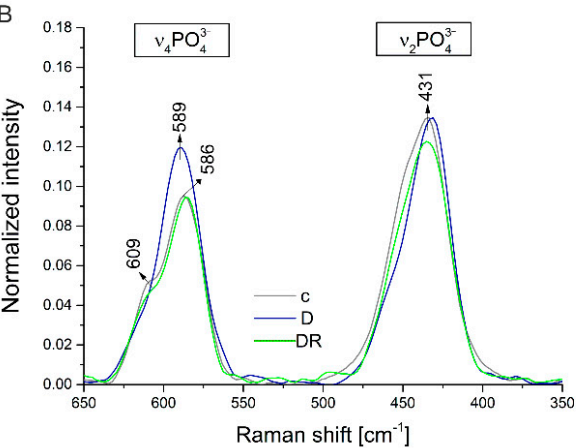

$\mathrm{D}$

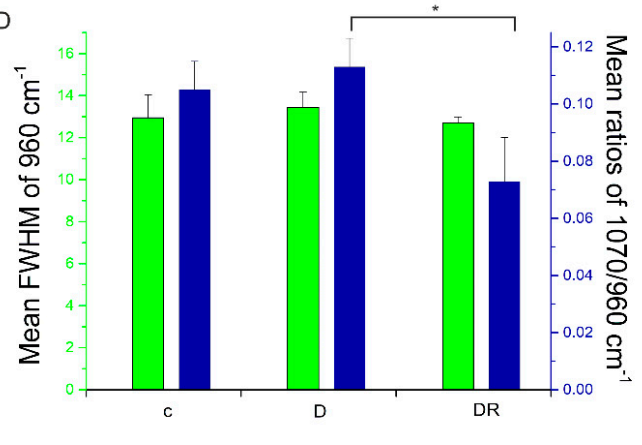

Figure 6. Averaged ( $n=10$ to each group) Raman spectra of dental enamel (A) from the control group (black line), after acid etching (blue line) and after the casein phosphopeptides and amorphous calcium phosphate (CPP-ACP) treatment (green line), (B) for $v_{2}$ and $v_{4}$ modes, (C) $v_{3}$ mode, of B-type carbonate and (D) corresponding full-widths at half maximum of the $960 \mathrm{~cm}^{-1}$ peak and the ratio of the integrated area under the bands of 1070 and $960 \mathrm{~cm}^{-1}$. Statistically significant (at $p<0.05$ ) differences between groups are marked with * c - control, D—demineralised group, DR—demineralised—then remineralised group. 
Symmetric bending vibrations of $\mathrm{PO}_{4}{ }^{3-}$ in the region of the $v_{2}$ mode appeared as a band at $\sim 430 \mathrm{~cm}^{-1}$ with a shoulder at $445 \mathrm{~cm}^{-1}$ for the control group (Figure 6B). After acid etching, a much sharper peak at $430 \mathrm{~cm}^{-1}$ was observed (Figure $6 \mathrm{~B}$ ). Comparing the spectra in the range of $650-350 \mathrm{~cm}^{-1}$, it was found that the intensity of the phosphate $v_{4}$ band slightly increased and revealed the spectral shift towards higher frequencies after acid treatment of enamel samples (Figure 6B). Interestingly, Raman spectra of enamel subjected to the varnish appeared very similar to the demineralised ones.

Loss of structure in the demineralised enamel samples was indicated by the low intensity of the $v_{1} \mathrm{CO}_{3}{ }^{2-}$ band (Figure $6 \mathrm{C}$ ). In the $v_{3} \mathrm{PO}_{4}{ }^{3-}$ region, the band centred near $1044 \mathrm{~cm}^{-1}$ was more intense than the band centred near $1070 \mathrm{~cm}^{-1}$, which suggested the superposition of a $v_{1} \mathrm{CO}_{3}{ }^{2-}$ band (Figure 6C). The mineral content, which is demonstrated by the intensity of the peak at $960 \mathrm{~cm}^{-1}$, decreased after demineralization (Figure 6A). Although there was no statistically significant difference between the investigated samples in the full-width at half maximum of the $960 \mathrm{~cm}^{-1}$ peak (Figure 6D), the intensity of the $v_{1} \mathrm{PO}_{4}{ }^{3-}$ band was almost ten times less for demineralized enamel than those seen for untreated enamel.

The ratio of the integrated area under bands 1070 and $960 \mathrm{~cm}^{-1}\left(1070 / 960 \mathrm{~cm}^{-1}\right)$ was used to analyse the carbonate content (Figure 6D). It revealed an increase in this ratio in the case of the demineralized sample when compared to that of the control group. The carbonate content evaluation exhibited a significant reduction in the experimental group subjected to the remineralization process with CPP-ACP treatment.

\subsubsection{XRD Pattern Analysis}

Reflection peak at $2 \theta=25.886 \mathrm{deg}(002)$ from XRD patterns (Figure 7A), was used to determine HA crystallites length in the z-axis (Figure 7B) and crystallinity index (Table 1) for all the examined groups. Reflection peaks at $2 \theta=32.912 \mathrm{deg}(300)$ and $2 \theta=25.886 \mathrm{deg}(002)$ were used to calculate the hexagonal lattice parameters for the control (c), demineralised (D), and demineralised then remineralised (DR) enamel (Table 1). Acid treatment caused perceptible shortening of crystallites in a $z$-crystallographic direction along with a significant $(p<0.05)$ decrease in the crystallinity value (Table 1). Varnish application (the DR group) lead to HA crystallites lengthening, however, they were still notably shorter than those of the control group. For the CI index (Table 1), the significant increase after varnish treatment was registered.

No significant differences were observed in the features of the lattice parameters among the groups studied. Only for the demineralised enamel significant $(p=0.0021)$ shortening of the $c$ lattice parameter was registered (Table 1).
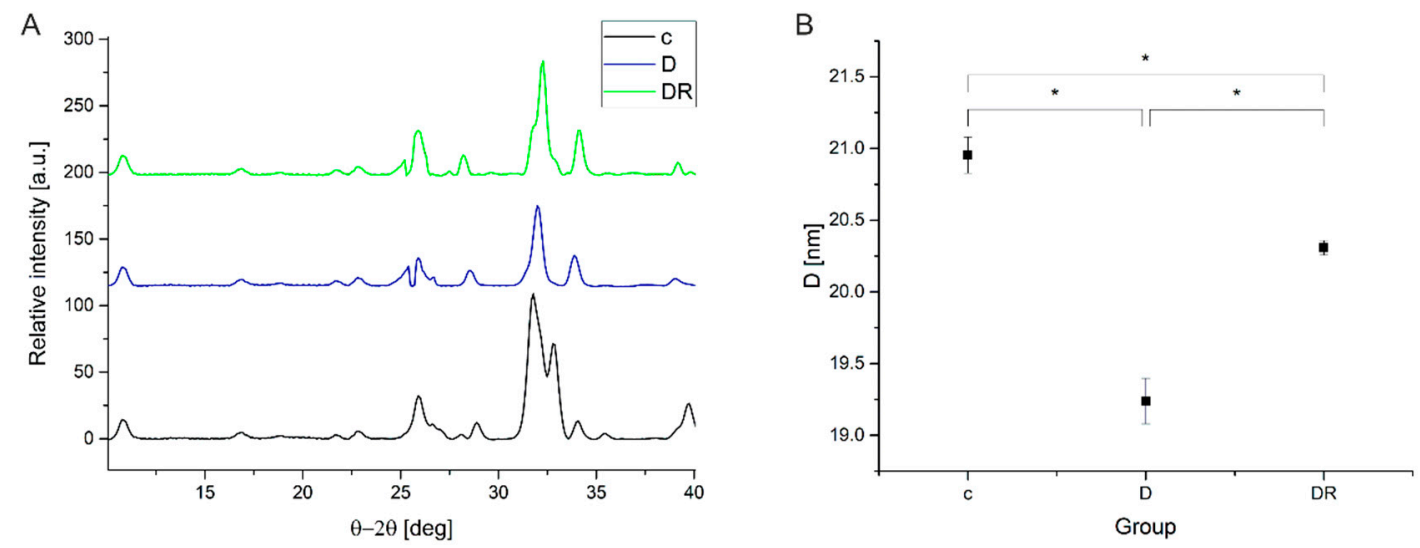

Figure 7. X-ray diffraction pattern of enamel hydroxyapatite (HA) crystals (A) and mean crystallite size of HA crystallites in the $\mathrm{z}$ crystallographic direction (B) with corresponding standard deviations. Significantly different groups (at $p<0.05$ ) are marked with * $c$ - control, D—demineralised group, $\mathrm{DR}$ - demineralised then remineralised group. 
Table 1. Mean values of enamel crystallinity index (CI) with corresponding standard deviations (SD).

\begin{tabular}{cccc}
\hline Group & CI & Lattice Parameter $\mathbf{a}=\mathbf{b}(\mathbf{n m})$ & Lattice Parameter c (nm) \\
\hline $\mathrm{c}$ & $0.238^{\mathrm{a}}( \pm 0.004)$ & $0.94559^{\mathrm{a}}( \pm 0.00062)$ & $0.68803^{\mathrm{a}}( \pm 0.00024)$ \\
$\mathrm{D}$ & $0.185^{\mathrm{b}}( \pm 0.005)$ & $0.94525^{\mathrm{a}}( \pm 0.00081)$ & $0.67816^{\mathrm{b}}( \pm 0.00086)$ \\
DR & $0.221^{\mathrm{c}}( \pm 0.002)$ & $0.94512^{\mathrm{a}}( \pm 0.00031)$ & $0.68821^{\mathrm{a}}( \pm 0.00023)$ \\
\hline
\end{tabular}

$\mathrm{a}, \mathrm{b}, \mathrm{c}$ - groups that do not differ at $p<0.05$; $\mathrm{c}$-control, D—demineralised group, DR-demineralised then remineralised group.

\subsubsection{Mechanical Features}

Demineralisation caused a significant decrease $(p<0.001)$ both in indentation elasticity (EIT) and indentation hardness (HIT), as presented in Figure 8A and 8B, respectively. Although still lower in comparison to the control, enamel surface was enhanced after varnish remineralisation, showing the increase in both investigated parameters. A $288 \%$ growth in HIT and a $67 \%$ growth in EIT were registered for the DR group in relation to the demineralised one. The enamel surface had become more rigid and more resistant against deformation, as the measurements revealed.
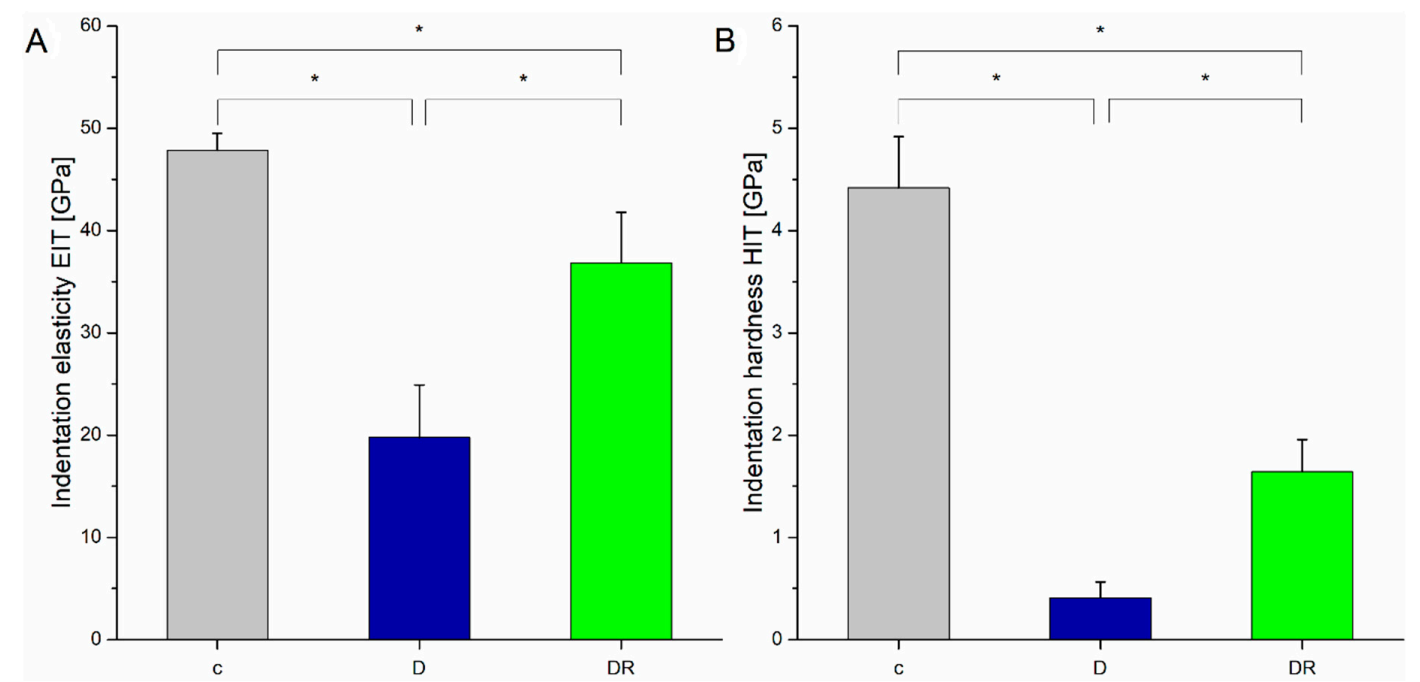

Figure 8. Indentation elasticity (A) and indentation hardness (B) for the control (c), demineralised (D), and demineralised then remineralised (DR) enamel surfaces. Statistically significant differences (at $p<$ 0.05) are marked with *. Raw data are in Figures S6 and S7.

\section{Discussion}

The presented study showed that, after $24 \mathrm{~h}$, fluoride varnish with CPP-ACP induced the partial regeneration of previously damaged enamel tissue, activating the formation of a new crystal layer. It was observed that the destroyed hydroxyapatite structure was largely rebuilt and the honeycomb-like structure was partially restored. The resulting surface was characterised by the greatest regularity, higher molecular and structural organisation and smoother surface when compared to that of the demineralised sample. Significant alterations in the morphology, mechanical properties, and chemical and molecular structures indicate that the remineralisation was the result of a range of processes observed on the surface layer of the enamel tissue.

A crystal is made up of several unit cells that are stacked in multiples along all possible axes and determine the crystal shape [38]. As observed in the presented research, acid-induced dissolution of minerals remodels the HA crystallite form and lowers the crystallinity index [10]. Increased disorder of the crystal structure and reduction of the crystallinity, as demonstrated by the broadening of the diffraction peaks, are not only the measure of the degree of mineralisation but are also connected with higher numbers of planar carbonate ions substituting for the tetrahedral phosphate ions in the apatite structure [39]. This is biologically important because an increase in carbonate content means an 
increase of the solubility of the dental apatite [40] and consequently formation of calcium deficient apatite. In light of the reported data regarding the correlation of carbonate content with enamel caries appearance, the high level of carbonate is thought to have a destabilizing effect [41] and may lead to creation of unstable apatite phases [42]. Therefore, lowering of the enamel crystallinity of our samples could be related to the observed increase in the $\mathrm{CO}_{3}{ }^{2-} / \mathrm{PO}_{4}{ }^{3-}$ band ratio.

Remineralization is the process of transferring anions and cations to nucleation sites, where the lattices, leading to mineral structures, are generated [10]. The lengthening of HA crystallites after varnish action (Figure 5 IC and IIC, Figure 7) indicates, that the remineralisation process resulted in the reconstruction of damaged HA crystallites and growth of new ones [6]. The above observations are also proven by the changes in FWHM of the (002) reflection peak and the degree of order of the crystalline matrix measured by the crystallinity index [43]; with higher CI indices, more ordered and more mineralised tissue might be observed. Additionally, the carbonate content evaluation, with regard to the integrated area under bands $\left(1070 / 960 \mathrm{~cm}^{-1}\right)$ calculated from Raman spectra, exhibited a significant reduction in concentration in $\mathrm{CO}_{3}{ }^{2-}$ in experimental group subjected to a remineralization process with varnish treatment.

Alterations in the crystalline structure directly translate into changes in the surface texture [44]. With respect to the calculated roughness parameters (Figure 3) and corresponding AFM and SEM scans (Figure 5I and II), varnish action led to the regeneration of a more uniform and compact surface layer. The characteristic enamel pattern had been largely rebuilt, resulting in a more homogenous surface. Though the enamel surface observed for the remineralised group was smoother compared to that of the eroded one, registered roughness was still higher compared to that of the control group. Detected fluctuations of roughness parameters for remineralised enamel are probably connected with the noticed amorphous material deposits [24,44,45].

It has been reported that fluoride substances containing $\mathrm{CPP}-\mathrm{ACP}$ are characterised by the highest fluoride and calcium ion release compared with other calcium phosphate substances and fluoride varnishes alone [46,47]. In supersaturated solutions, where the fluoride is available together with calcium and phosphate, fluoride ions are incorporated into the apatite crystal lattice [47], and form FA. They replace the hydroxyl ions located at the centre of the calcium triangles. While the hydroxyl ion is too large to fit into this place, the oxygen is displaced from the plane of the calcium triangles and the $\mathrm{F}$ ions are surrounded by calcium ions. This results in a reduction in the volume of the unit cell [47] (HA: $\mathrm{a}=\mathrm{b}=9432 \AA$ and $\mathrm{c}=6881 \AA$; FA: $\mathrm{a}=\mathrm{b}=9367 \AA$ and $\mathrm{c}=6884 \AA$ [48]) and contributes to a more compact lattice and stronger electrostatic bonds between calcium and $\mathrm{F}$ ions than between calcium and $\mathrm{OH}$ ions [49]. FA is more stable than HA and more resistant against acids [48], which can be translated into changes in the mechanical features. The observed increase in the indentation hardness and indentation elasticity after varnish action may suggest the $\mathrm{OH}^{-}$substitution by $\mathrm{F}^{-}$. Nevertheless, the values of lattice parameters and spectroscopy measurements contradict the occurrence of that process. Unit cell dimensions as well as low fluoride levels suggest that $\mathrm{OH}$ groups in the HA structure have not been replaced by fluoride ions, or the range of the process was not extensive. A growth in both the hardness and the elasticity revealed by nanoindentation measurements may therefore be associated with mentioned reconstruction of the HA structure and the growth of the new, strong crystals.

It should be noted, that mechanical parameters of tooth enamel are strongly related to their mineral content $[5,50,51]$. Loss of the minerals induced by acid application is known to cause a reduction in the hardness and elasticity of the enamel surface $[44,52,53]$; this was also noted in the present study. It was found that artificial demineralization, recognised as a reduction in crystallographic texture (preferred orientation), was coupled with the loss of mineral mass [54]. As mentioned, the main building blocks of enamel are calcium and phosphate ions, thus, the determination of their content allowed us to notice a significant decrease in the $\mathrm{Ca} / \mathrm{P}$ ratio after acid treatment. The reduction of the $\mathrm{Ca} / \mathrm{P}$ ratio was primarily due to a decrease in the amount of calcium ions in the hydroxyapatite structure, these ions are notably vulnerable to orthophosphoric acid during the first few minutes of its action [55]. The use of varnish caused a significant rise in the mineral content and return of the 
$\mathrm{Ca} / \mathrm{P}$ ratio to the initial value. The observed effect is probably directly connected to casein features, as its micelles serve as carriers of calcium phosphate, providing the tissue with a bioavailable source of calcium and phosphate ions [56], thereby increasing the extent of tissue calcification [57]. What is more, casein phosphopeptide can deliver amorphous calcium phosphate and help the ACP to bind with dental enamel [58], supplying it with the necessary elements. A similar pattern concerning Ca and $\mathrm{P}$ content changes, as a consequence of enamel demineralisation and then remineralisation, was observed by Zhang et al. [6], where the morphological, chemical, and crystallographic characters of the remineralised surface were investigated. Our measurements showed that for the non-treated enamel, the Ca peak observed in the EDS spectra had a higher intensity than the P peak, while after demineralisation, both peak maximums were close to each other. In contrast, remineralisation brought the contents of elements almost to their initial state, hence, CPP-ACPF was found to re-harden the acid-treated enamel, however, it was not possible to recover it to its previous form.

According to most of the literature, the use of preparations containing CPP, ACP, and F causes an increase in mechanical parameters of enamel [44,52,53], in contrast to [59] in which a similar effect was not observed. This is probably related to the types of mechanical tests used and the range of erosion. Shorter acid exposure times cause less erosion depth in enamel tissue. Microhardness or bending tests are not able to detect differences in mechanical parameters if the depth of erosion is in the nanometre scale [60].

While our findings provide evidence of how fluoride substances containing natural compounds in the form of CPP-ACP act on the enamel surface, the presented work had some limitations that require comment. Primarily, the presented research involved in vitro studies and cannot be directly translated into a real conditions. Despite the that fact that the prevailing environment of the oral cavity was mimicked to a large extent, the range of the introduced effects may differ from those shown. Another potential weakness of our study is related to sample preparation. The enamel surfaces examined in this in vitro experiment belong to the inner part of enamel tissue, which, contrary to the prismless and highly mineralised surface of permanent teeth, is characterised by a prismatic structure and lower mineralization level [61,62]. It might be assumed that the dynamics of acid and varnish action may differ [63]. The processes of cutting and polishing were, nonetheless, indispensable as they made the enamel samples more uniform.

\section{Conclusions}

CPP-ACP fluoride varnish acted as an instigator of the remineralisation process, initiating the formation of a new crystal layer with parameters similar to those of the initial enamel. Surface analysis conducted revealed significant alterations in the morphology, mechanical properties, and chemical and molecular structures of the studied enamel tissue as a result of the processes that occurred on the surface layer.

Supplementary Materials: The following are available online at http://www.mdpi.com/2218-273X/10/5/765/s1, Figure S1: An averaged values of the average roughness (Sa) for the control (c) demineralised (D) and demineralised-remineralised (DR) enamel with corresponding standard deviations (whiskers) and mean values (black square), Figure S2: An averaged values of the root mean squared roughness $\left(\mathrm{S}_{\mathrm{q}}\right)$ for the control (c) demineralised (D) and demineralised-remineralised (DR) enamel with corresponding standard deviations (whiskers) and mean values (black square), Figure S3: An averaged values of the vertical distance between the maximum height and the maximum depth $\left(\mathrm{S}_{\mathrm{z}}\right)$ for the control (c) demineralised (D) and demineralised-remineralised (DR) enamel with corresponding standard deviations (whiskers) and mean values (black square), Figure S4: An averaged values of the average height calculated over five highest peaks and five deepest valleys $\left(\mathrm{S}_{10}\right)$ for the control (c) demineralised (D) and demineralised-remineralised (DR) enamel with corresponding standard deviations (whiskers) and mean values (black square), Figure S5: Ca/P ratios determined for the analysed samples from the control (c), demineralised (D) and demineralised-remineralised (DR) groups with corresponding standard deviations (whiskers) and mean values (black square), Figure S6: Indentation elasticity (EIT) values determined for the analysed samples from the control (c), demineralised (D) and demineralised-remineralised (DR) groups with corresponding standard deviations (whiskers) and mean values (black square), Figure S7: Indentation hardness (HIT) values determined for the analysed samples from the control (c), demineralised (D) and demineralised-remineralised (DR) groups with corresponding standard deviations (whiskers) and mean values (black square). 
Author Contributions: Conceptualization, I.Ś., M.M.-B., and D.K.; Methodology, I.Ś., S.M., M.A., and M.Ś.; Validation, E.T., M.M.-B., and I.Ś.; Formal Analysis, I.Ś. and M.A.; Investigation, I.Ś, M.A., M.Ś, A.P., J.B., K.C., and D.K..; Resources, D.K., M.M.-B., K.G., and D.K.; Data Curation, I.Ś; Writing-Original Draft Preparation, I.Ś., and M.A.; Writing-Review and Editing, M.A. and S.M.; Visualization, I.Ś. and M.Ś.; Supervision, E.T.; Project Administration, I.Ś.; Funding Acquisition, M.M.-B. All authors have read and agreed to the published version of the manuscript.

Funding: This research received no external funding.

Acknowledgments: I.S would like to thank Wojciech Grudziński for taking a photo presented at Figure 2 and Wiesław I. Gruszecki for sharing the equipment necessary to conduct a part of the research. The equipment was purchased thanks to the financial support of the European Development Fund in the framework of the Development of Eastern Poland Operational Programme.

Conflicts of Interest: The authors declare no conflict of interest.

\section{References}

1. Aoba, T. Recent observations on enamel crystal formation during mammalian amelogenesis. Anat. Rec. Adv. Integr. Anat. Evol. Boil. 1996, 245, 208-218. [CrossRef]

2. Hong, H.; Tie, L.; Jian, T. The crystal characteristics of enamel and dentin by XRD method. J. Wuhan Univ. Technol. 2006, 21, 9-12.

3. Combes, C.; Cazalbou, S.; Rey, C. Apatite Biominerals. Minerals 2016, 6, 34. [CrossRef]

4. Hemingway, C.A.; Parker, D.M.; Addy, M.; Barbour, M.E. Erosion of enamel by non-carbonated soft drinks with and without toothbrushing abrasion. Br. Dent. J. 2006, 201, 447-450. [CrossRef] [PubMed]

5. Brito, J.S.; Neto, A.P.D.S.; Silva, L.; Menezes, R.; Araújo, N.; Carneiro, V.; Moreno, L.M.; Miranda, J.; Álvares, P.; Nevares, G. Analysis of Dental Enamel Surface Submitted to Fruit Juice Plus Soymilk by Micro X-Ray Fluorescence: In Vitro Study. Sci. World J. 2016, 2016, 1-8. [CrossRef]

6. Zhang, L.-L.; Li, J.-Y.; Zhou, X.-D.; Cui, F.-Z.; Wei, L. Chemical and crystallographic study of remineralized surface on initial carious enamel treated withGalla chinensis. Scanning 2010, 31, 236-245. [CrossRef]

7. Muñoz, C.A.; Torrado, A.; Valiente, M.; Zhang, W.; Li, Y. Remineralization Potential of a New Toothpaste Formulation: An In-Vitro Study. J. Contemp. Dent. Pr. 2004, 5, 18-30. [CrossRef]

8. Sa, Y.; Liang, S.; Ma, X.; Lu, S.; Wang, Z.; Jiang, T.; Wang, Y. Compositional, structural and mechanical comparisons of normal enamel and hypomaturation enamel. Acta Biomater. 2014, 10, 5169-5177. [CrossRef] [PubMed]

9. Kuriakose, S.; Sundaresan, C.; Mathai, V.; Khosla, E.; Gaffoor, F.M.A. A comparative study of salivary buffering capacity, flow rate, resting $\mathrm{pH}$, and salivary Immunoglobulin A in children with rampant caries and caries-resistant children. J. Indian Soc. Pedod. Prev. Dent. 2013, 31, 69-73. [CrossRef]

10. Ehrlich, H.; Koutsoukos, P.G.; Demadis, K.D.; Pokrovsky, O.S. Principles of demineralization: Modern strategies for the isolation of organic frameworks. Micron 2008, 39, 1062-1091. [CrossRef]

11. Kim, J.W.; Lee, R.; Chan, K.H.; Jew, J.M.; Fried, D. Influence of a pulsed CO2 laser operating at $9.4 \mu \mathrm{m}$ on the surface morphology, reflectivity, and acid resistance of dental enamel below the threshold for melting. J. Biomed. Opt. 2017, 22, 1-7. [CrossRef] [PubMed]

12. Nair, A.S.; Kumar, R.K.; Philip, S.T.; Ahameed, S.S.; Punnathara, S.; Peter, J. A Comparative Analysis of Caries Inhibitory Effect of Remineralizing Agents on Human Enamel Treated With Er:YAG Laser: An In-vitro Atomic Emission Spectrometry Analysis. J. Clin. Diagn. Res. 2016, 10, ZC10-ZC13. [CrossRef] [PubMed]

13. Tuloglu, N.; Bayrak, S.; Tunc, E.S.; Ozer, F. Effect of fluoride varnish with added casein phosphopeptide-amorphous calcium phosphate on the acid resistance of the primary enamel. BMC Oral Heal. 2016, 16, 1-7. [CrossRef] [PubMed]

14. Hemmati, S.; Dehghan, H. Effect of diode and CO2 lasers combined with sodium fluoride varnish on microhardness of deciduous enamel. Majallahi Danishgahi Ulumi Pizishkii Mazandaran 2016, 26, 44-54.

15. Talaat, D.A.; Mahmoud, A. Acid Resistance of Enamel Subsurface Lesions Treated with Casein Phosphopeptide Amorphous Calcium Phosphate Fluoride. J. Dent. Child. (Chicago, Ill.) 2015, 82, 70-75.

16. Memarpour, M.; Soltanimehr, E.; Sattarahmady, N. Efficacy of calcium- and fluoride-containing materials for the remineralization of primary teeth with early enamel lesion. Microsc. Res. Tech. 2015, 78, 801-806. [CrossRef] 
17. Reynolds, E.C. Anticariogenic complexes of amorphous calcium phosphate stabilized by casein phosphopeptides: A review. Speéc. Care Dent. 1998, 18, 8-16. [CrossRef]

18. Farooq, I.; Moheet, I.A.; Imran, Z.; Farooq, U. A review of novel dental caries preventive material: Casein phosphopeptide-amorphous calcium phosphate (CPP-ACP) complex. King Saud Univ. J. Dent. Sci. 2013, 4, 47-51. [CrossRef]

19. Aoba, T. The Effect of Fluoride on Apatite Structure and Growth. Crit. Rev. Oral Boil. Med. 1997, 8, 136-153. [CrossRef]

20. Tao, S.; Zhu, Y.; Yuan, H.; Tao, S.; Cheng, Y.; Li, J.; He, L. Efficacy of fluorides and CPP-ACP vs fluorides monotherapy on early caries lesions: A systematic review and meta-analysis. PLoS ONE 2018, 13, e0196660. [CrossRef]

21. Swietlicka, I.; Muszyński, S.; Tomaszewska, E.; Dobrowolski, P.; Kwaśniewska, A.; Świetlicki, M.; Skic, A.; Gołacki, K. Prenatally administered HMB modifies the enamel surface roughness in spiny mice offspring: An atomic force microscopy study. Arch. Oral Boil. 2016, 70, 24-31. [CrossRef]

22. Bertacci, A.; Lucchese, A.; Taddei, P.; Gherlone, E.F.; Chersoni, S. Enamel structural changes induced by hydrochloric and phosphoric acid treatment. J. Appl. Biomater. Funct. Mater. 2014, 12, 240-247. [CrossRef] [PubMed]

23. Fava, M.; Myaki, S.I.; Arana-Chavez, V.E.; Fava-De-Moraes, F. Effects of a non-rinse conditioner on the enamel of primary teeth. Braz. Dent. J. 2004, 14, 168-171. [CrossRef] [PubMed]

24. Poggio, C.; Lombardini, M.; Vigorelli, P.; Ceci, M. Analysis of dentin/enamel remineralization by a CPP-ACP paste: AFM and SEM study. Scanning 2013, 35, 366-374. [CrossRef] [PubMed]

25. Delbem, A.C.B.; Bergamaschi, M.; Sassaki, K.T.; Cunha, R.F. Effect of fluoridated varnish and silver diamine fluoride solution on enamel demineralization: pH-cycling study. J. Appl. Oral Sci. 2006, 14, 88-92. [CrossRef] [PubMed]

26. El Feninat, F.; Elouatik, S.; Ellis, T.; Sacher, E.; Stangel, I. Quantitative assessment of surface roughness as measured by AFM: Application to polished human dentin. Appl. Surf. Sci. 2001, 183, 205-215. [CrossRef]

27. Mei, L.; Busscher, H.J.; Van Der Mei, H.C.; Ren, Y. Influence of surface roughness on streptococcal adhesion forces to composite resins. Dent. Mater. 2011, 27, 770-778. [CrossRef]

28. Pezzotti, G. Raman spectroscopy of piezoelectrics. J. Appl. Phys. 2013, 113, 1-78. [CrossRef]

29. Tsuda, H.; Arends, J. Orientational Micro-Raman Spectroscopy on Hydroxyapatite Single Crystals and Human Enamel Crystallites. J. Dent. Res. 1994, 73, 1703-1710. [CrossRef]

30. Adachi, T.; Pezzotti, G.; Yamamoto, T.; Ichioka, H.; Boffelli, M.; Zhu, W.; Kanamura, N. Vibrational algorithms for quantitative crystallographic analyses of hydroxyapatite-based biomaterials: II, application to decayed human teeth. Anal. Bioanal. Chem. 2015, 407, 3343-3356. [CrossRef]

31. Pezzotti, G.; Zhu, W.; Boffelli, M.; Adachi, T.; Ichioka, H.; Yamamoto, T.; Marunaka, Y.; Kanamura, N. Vibrational algorithms for quantitative crystallographic analyses of hydroxyapatite-based biomaterials: I, theoretical foundations. Anal. Bioanal. Chem. 2015, 407, 3325-3342. [CrossRef]

32. Goldberg, M.; Kellermann, O.; Dimitrova-Nakov, S.; Harichane, Y.; Baudry, A. Comparative studies between mice molars and incisors are required to draw an overview of enamel structural complexity. Front. Physiol. 2014, 5. [CrossRef]

33. Rusu, V.M.; Ng, C.H.; Wilke, M.; Tiersch, B.; Fratzl, P.; Peter, M.G. Size controlled hydroxyapatite nanoparticles as self-organised organic-inorganic composite materials. Biomaterials 2005, 26, 5414-5426. [CrossRef]

34. Muszyński, S.; Tomaszewska, E.; Dobrowolski, P.; Kwiecień, M.; Wiącek, D.; Świetlicka, I.; Skibińska, M.; Szymańska-Chargot, M.; Orzeł, J.; Świetlicki, M.; et al. Analysis of bone osteometry, mineralization, mechanical and histomorphometrical properties of tibiotarsus in broiler chickens demonstrates a influence of dietary chickpea seeds (Cicer arietinum L.) inclusion as a primary protein source. PLoS ONE 2018, 13, e0208921. [CrossRef]

35. Reyes-Gasga, J.; Martinez-Piñeiro, E.L.; Rodríguez-Álvarez, G.; Tiznado-Orozco, G.E.; García-García, R.; Brès, E.F. XRD and FTIR crystallinity indices in sound human tooth enamel and synthetic hydroxyapatite. Mater. Sci. Eng. C 2013, 33, 4568-4574. [CrossRef]

36. Wang, Y.; Shi, J. Effects of water molecules on tribological behavior and property measurements in nano-indentation processes-a numerical analysis. Nanoscale Res. Lett. 2013, 8, 1-14. [CrossRef]

37. Spizzirri, P.; Cochrane, N.; Prawer, S.; Reynolds, E.C. A Comparative Study of Carbonate Determination in Human Teeth Using Raman Spectroscopy. Caries Res. 2012, 46, 353-360. [CrossRef] 
38. Raue, L.; Gersdorff, N.; Rödiger, M.; Klein, H. New insights in prism orientation within human enamel. Arch. Oral Boil. 2012, 57, 271-276. [CrossRef]

39. Leventouri, T.; Antonakos, A.; Kyriacou, A.; Venturelli, R.; Liarokapis, E.; Perdikatsis, V. Crystal Structure Studies of Human Dental Apatite as a Function of Age. Int. J. Biomater. 2009, 2009, 1-6. [CrossRef]

40. Awonusi, A.; Morris, M.D.; Tecklenburg, M.M. Carbonate Assignment and Calibration in the Raman Spectrum of Apatite. Calcif. Tissue Int. 2007, 81, 46-52. [CrossRef]

41. Weatherell, T.; Robinson, C.; Hiller, C.; Weatherell, I. Distribution of Carbonate in Thin Sections of Dental Enamel. Caries Res. 1968, 2, 1-9. [CrossRef] [PubMed]

42. Clasen, A.S.; Ruyter, I. Quantitative determination of type A and type B carbonate in human deciduous and permanent enamel by means of Fourier transform infrared spectrometry. Adv. Dent. Res. 1997, 11, 523-527. [CrossRef] [PubMed]

43. Vargas-Becerril, N.; Reyes-Gasga, J.; García-García, R. Evaluation of crystalline indexes obtained through infrared spectroscopy and x-ray diffraction in thermally treated human tooth samples. Mater. Sci. Eng. C 2019, 97, 644-649. [CrossRef]

44. Wang, C.; Huang, S.; Liu, Y.; Li, J.; Yu, H. The CPP-ACP relieved enamel erosion from a carbonated soft beverage: An in vitro AFM and XRD study. Arch. Oral Boil. 2014, 59, 277-282. [CrossRef]

45. Llena, C.; Esteve, I.; Rodríguez-Lozano, F.J.; Forner, L. The application of casein phosphopeptide and amorphous calcium phosphate with fluoride (CPP-ACPF) for restoring mineral loss after dental bleaching with hydrogen or carbamide peroxide: An in vitro study. Ann. Anat.-Anat. Anz. 2019, 225, 48-53. [CrossRef]

46. Cochrane, N.; Shen, P.; Yuan, Y.; Reynolds, E.; Reynolds, E.C. Ion release from calcium and fluoride containing dental varnishes. Aust. Dent. J. 2014, 59, 100-105. [CrossRef]

47. Sleibi, A.; Tappuni, A.; Karpukhina, N.G.; Hill, R.G.; Baysan, A. A comparative evaluation of ion release characteristics of three different dental varnishes containing fluoride either with CPP-ACP or bioactive glass. Dent. Mater. 2019, 35, 1695-1705. [CrossRef]

48. Mathew, M.; Takagi, S. Structures of bological minerals in dental research. J. Res. Natl. Inst. Stan. 2001, 106, 1035-1044. [CrossRef]

49. Overgaard, S. Calcium phosphate coatings for fixation of bone implants: Evaluated mechanically and histologically by stereological methods. Acta Orthop. Scand. 2000, 71, 1-74. [CrossRef]

50. AlKattan, R.; Lippert, F.; Tang, Q.; Eckert, G.J.; Ando, M. The influence of hardness and chemical composition on enamel demineralization and subsequent remineralization. J. Dent. 2018, 75, 34-40. [CrossRef]

51. Cuy, J.; Mann, A.; Livi, K.; Teaford, M.; Weihs, T.P. Nanoindentation mapping of the mechanical properties of human molar tooth enamel. Arch. Oral Boil. 2002, 47, 281-291. [CrossRef]

52. Zheng, L.; Peng, J.; Zheng, J.; Liu, D.; Zhou, Z. Surface properties of eroded human primary and permanent enamel and the possible remineralization influence of CPP-ACP. Wear 2017, 376, 251-258. [CrossRef]

53. Zheng, L.; Zheng, J.; Zhang, Y.F.; Qian, L.M.; Zhou, Z. Effect of CPP-ACP on the remineralization of acid-eroded human tooth enamel: Nanomechanical properties and microtribological behaviour study. J. Phys. D: Appl. Phys. 2013, 46,1-9. [CrossRef]

54. Siddiqui, S.; Anderson, P.; Al-Jawad, M. Recovery of Crystallographic Texture in Remineralized Dental Enamel. PLoS ONE 2014, 9, e108879. [CrossRef]

55. Torres-Rodríguez, C.; Navarro, A.B.; Sánchez-Sánchez, P.; González-López, S. Selective removal of mineral and organic components of bovine enamel by phosphoric acid. J. Adhes Dent. 2012, 14, 329-334.

56. Cross, K.J.; Huq, N.L.; Reynolds, E.C. Casein phosphopeptide-amorphous calcium phosphate nanocomplexes: A structural model. Biochemistry 2016, 55, 4316-4325. [CrossRef]

57. Gerber, H.W.; Jost, R. Casein phosphopeptides: Their effect on calcification ofin vitro cultured embryonic rat bone. Calcif. Tissue Int. 1986, 38, 350-357. [CrossRef]

58. Reynolds, E.C.; Black, C.L.; Cai, F.; Cross, K.J.; Eakins, D.; Huq, N.L.; Morgan, M.V.; Nowicki, A.; Perich, J.W.; Riley, P.F.; et al. Advances in enamel remineralization: Casein phosphopeptide-amorphous calcium phosphate. J. Clin. Dent. 1999, 10, 86-88.

59. Wang, X.; Megert, B.; Hellwig, E.; Neuhaus, K.W.; Lussi, A. Preventing erosion with novel agents. J. Dent. 2011, 39, 163-170. [CrossRef]

60. Cheng, Z.-J.; Wang, X.-M.; Cui, F.-Z.; Ge, J.; Yan, J.-X. The enamel softening and loss during early erosion studied by AFM, SEM and nanoindentation. Biomed. Mater. 2009, 4, 1-7. [CrossRef] 
61. Bartlett, J.D. Dental Enamel Development: Proteinases and Their Enamel Matrix Substrates. ISRN Dent. 2013, 2013, 1-24. [CrossRef]

62. Gibson, C.W. The amelogenin proteins and enamel development in humans and mice. J. Oral Biosci. 2011, 53, 248-256. [CrossRef]

63. Finke, M.; Jandt, K.D.; Parker, D.M. The Early Stages of Native Enamel Dissolution Studied with Atomic Force Microscopy. J. Colloid Interface Sci. 2000, 232, 156-164. [CrossRef]

(C) 2020 by the authors. Licensee MDPI, Basel, Switzerland. This article is an open access article distributed under the terms and conditions of the Creative Commons Attribution (CC BY) license (http://creativecommons.org/licenses/by/4.0/). 